Article

\title{
Characterization of Two Small Heat Shock Protein Genes (Hsp17.4 and Hs20.3) from Sitodiplosis mosellana, and Their Expression Regulation during Diapause
}

\author{
Jiajia Zhao ${ }^{1,+}$, Qitong Huang ${ }^{1,+} \oplus$, Guojun Zhang ${ }^{1}$, Keyan Zhu-Salzman ${ }^{2, *}$ and Weining Cheng ${ }^{1, *}$ \\ 1 Key Laboratory of Plant Protection Resources \& Pest Management of the Ministry of Education, \\ College of Plant Protection, Northwest A\&F University, Yangling 712100, China; \\ b20193190927@cau.edu.cn (J.Z.); 13760637249hqt@nwafu.edu.cn (Q.H.); zhangguojun97@nwafu.edu.cn (G.Z.) \\ 2 Department of Entomology, Texas A\&M University, College Station, TX 77843, USA \\ * Correspondence: ksalzman@tamu.edu (K.Z.-S.); chengwn@nwsuaf.edu.cn (W.C.) \\ + These two authors contributed equally to this study.
}

check for updates

Citation: Zhao, J.; Huang, Q.; Zhang, G.; Zhu-Salzman, K.;

Cheng, W. Characterization of Two Small Heat Shock Protein Genes (Hsp17.4 and Hs20.3) from Sitodiplosis mosellana, and Their Expression Regulation during Diapause. Insects 2021, 12, 119. https://doi.org/10. 3390/insects12020119

Received: 29 December 2020

Accepted: 25 January 2021

Published: 29 January 2021

Publisher's Note: MDPI stays neutral with regard to jurisdictional claims in published maps and institutional affiliations.

Copyright: (c) 2021 by the authors. Licensee MDPI, Basel, Switzerland. This article is an open access article distributed under the terms and conditions of the Creative Commons Attribution (CC BY) license (https:// creativecommons.org/licenses/by/ $4.0 /)$.
Simple Summary: Small heat shock proteins (sHsps) play important roles in thermal adaptation of various organisms, and insect diapause. Sitodiplosis mosellana, a key pest of wheat worldwide, undergoes obligatory larval diapause in soil to survive adverse temperature extremes during hot summers and cold winters. The objectives of this study were to characterize two $s H s p$ genes from S. mosellana (SmHsp17.4 and SmHsp20.3), and determine their expression in response to diapause, extreme high/low temperatures, or 20-hydroxyecdysone (20E) treatment. Expression of SmHsp17.4 was down-regulated upon entry into diapause, but up-regulated during the shift to post-diapause quiescence. In contrast, expression of SmHsp20.3 was not affected by entry into diapause, but was pronounced during summer and winter. Furthermore, transcripts of both SmHsps were highly responsive to heat $\left(\geq 35{ }^{\circ} \mathrm{C}\right)$ and cold $\left(\leq-5{ }^{\circ} \mathrm{C}\right)$ during diapause, and topical application of $20 \mathrm{E}$ on diapausing larvae also induced $S m H s p 17.4$ in a dose-dependent manner. Notably, the recombinant SmHsp17.4 and SmHsp20.3 exhibited significant molecular chaperone activity. In conclusion, SmHsp17.4 and SmHsp20.3 play essential roles in heat/cold adaptation, and 20E-mediated SmHsp17.4 was also likely involved in diapause termination. Results have improved our understanding of the molecular mechanism underlying diapause and related stress tolerance in S. mosellana.

Abstract: Sitodiplosis mosellana, a periodic but devastating wheat pest that escapes temperature extremes in summer and winter by undergoing obligatory diapause. To determine the roles of small heat shock proteins (sHsps) in diapause of $S$. mosellana, we characterized two sHsp genes, SmHsp17.4 and SmHsp20.3, from this species. Both SmHsps contained the conserved $\alpha$-crystallin domain and the carboxy-terminal I/VXI/V motif of the sHsp family. SmHsp17.4 had one intron while SmHsp20.3 had none. Quantitative PCR revealed that SmHsp17.4 expression decreased after diapause initiation, but substantially increased during transition to post-diapause quiescence. In contrast, SmHsp20.3 expression was not affected by entry of diapause, but was clearly up-regulated during summer and winter. Short-term more severe heat-stress $\left(\geq 35^{\circ} \mathrm{C}\right)$ of over-summering larvae or cold-stress $\left(\leq-5^{\circ} \mathrm{C}\right)$ of over-wintering larvae could stimulate higher expression of both genes, and $S m H s p 17.4$ was more responsive to cold stress while $S m H s p 20.3$ was more sensitive to heat stress. Notably, transcription of $S m H s p 17.4$, but not $S m H s p 20.3$, in diapausing larvae was inducible by 20hydroxyecdysone (20E). Recombinant SmHsp17.4 and SmHsp20.3 proteins also displayed significant chaperone functionality. These findings suggest that both $S m H s p s$ play key roles in stress tolerance during diapause; and 20E-regulated $S m H s p 17.4$ was also likely involved in diapause termination.

Keywords: Sitodiplosis mosellana; Hsp17.4; Hsp20.3; diapause; stress tolerance; ecdysone 


\section{Introduction}

In response to various environmental stresses such as extreme temperatures, heavy metals, pesticides, UV-A light, and anoxia, almost all organisms synthesize a set of proteins called heat shock proteins (Hsps) [1-5]. These molecular chaperones, up-regulated during stresses, promote correct refolding and thus prevent irreversible aggregation of denatured proteins. They are traditionally divided into several families based on molecular weight, including Hsp100, Hsp90, Hsp70, Hsp60, Hsp40, and small Hsps (sHsps) [6,7].

sHsps are ATP-independent proteins with molecular weights ranging from 12 to $43 \mathrm{kDa}[8,9]$. Compared to other Hsps, these proteins generally exhibit a greater variation in size, sequence, and function $[10,11]$. Ten sHsps were identified from the human genome and more than $10 \mathrm{sHsps}$ were found in genomes of Bombyx mori, Drosophila melanogaster, and Tribolium castaneum $[12,13]$. They all possess a conserved $\alpha$-crystallin domain containing 80-100 amino acid residues despite variable $\mathrm{N}$ - and C-terminal sequences. The $\alpha$-crystallin domain, rich in $\beta$-strands, is thought to be crucial for maintaining chaperone activity of sHsps [14]. Apart from the primary chaperone function, sHsps participate in diverse fundamental cellular processes, involving cell growth, differentiation and apoptosis [15], membrane fluidity [16], and cytoskeletal organization [17,18]. They are also therapeutic targets and biomarkers of many human diseases [19,20].

Recent studies have shown that sHsps in insects are also involved in diapause, an adaptive strategy that insects develop to survive seasonal adverse environmental conditions such as temperature extremes [21,22]. For instance, in the flesh fly Sarcophaga crassipalpis, transcripts of $H s p 23$ are most abundant in diapausing pupae, and decline when diapause ends and post-diapause development begins [23,24]. Up-regulation of sHsps during diapause have also been observed in several other insects, such as Delia antiqua Hsp23 [25], Calliphora vicina Hsps23 and 24 [26], Helicoverpa armigera Hsp21.4, and Grapholita molesta Hsps18.9, 21.3, 21.7 and 31.8. In contrast, H. armigera Hsp20.7, G. molesta Hsp21.4, and Sesamia nonagrioides Hsp20.8 are down-regulated during diapause [27-29], and some other sHsps are not affected by diapause [30-32]. Thus roles played by sHsps in diapause might differ greatly amongst protein family members and insect species.

It has been suggested that functions of Hsps are regulated by ecdysone. Several sHsp genes, such as D. melanogaster Hsps23 and 27 [33,34], Ceratitis capitata Hsp27 [35], and Apis cerana Hsps23 and 24.2 [36], are up-regulated by 20-hydroxyecdysone (20E) during normal development. The ecdysone-responsive element has been found in the promoter region of C. capitata Hsp27 [35]. However, little information is available on the 20E regulation of sHsps during diapause.

The orange wheat blossom midge Sitodiplosis mosellana (Géhin) (Diptera: Cecidomyiidae), a widespread periodic wheat pest across Asia, Europe, and North America, causes severe damage in years of high infestation [37-39]. It is a univoltine species and undergoes an obligatory larval diapause in soil. Adults emerge and lay eggs in late April in most of northern China [40]. Hatched larvae feed on developing seeds. Mature 3rd instar larvae drop from wheat ears to the ground during middle to late May, and burrow into soil to form round diapausing cocoons. They do not exit cocoons until the mid-March of the following year. Therefore, the long period of diapause enables this insect to escape unfavorable temperature extremes during hot summers and cold winters. To date, sHsps have been widely considered to be the most crucial players in heat/cold adaptation and insect diapause, although the function of sHsps in diapausing S. mosellana remains to be investigated.

In the present study, we cloned and characterized two sHsp genes from S. mosellana (SmHsp17.4 and SmHsp20.3). We profiled their expression during diapause and examined how excess short-term extreme temperatures or 20E treatment impacted expression patterns. In addition, we explored the potential chaperone activities of the recombinant proteins in vitro. 


\section{Materials and Methods}

\subsection{Experimental Insects}

Pre-diapausing 3rd instar larvae of $S$. mosellana were collected from severely infested wheat ears from a wheat field on 20 May 2016. Wheat ears containing pre-diapausing 3rd instar larvae were also harvested in large quantity and put on moist soil in a field insectary in Northwest A\&F University, Yangling $\left(34^{\circ} 16^{\prime} \mathrm{N}, 108^{\circ} 4^{\prime} \mathrm{E}\right)$, Shaanxi, China, to facilitate larvae to enter diapause. Successful diapause initiation is indicated by formation of larval cocoons. Our earlier study showed that almost all cocooned larvae collected in December or later have terminated diapause and entered post-diapause quiescence [41]. Cocooned larvae at diapausing and quiescent stages, and post-diapause developing larvae (i.e., larvae exiting cocoons) were successively collected from soil in the insectary following the procedure we previously developed [42]. All larvae collected were frozen in liquid nitrogen and then stored at $-80{ }^{\circ} \mathrm{C}$ for later RNA extraction.

\subsection{RNA Extraction, cDNA Synthesis, and gDNA Isolation}

Total RNA was extracted from 20 pre-diapausing larvae using the TRNizol RNA Isolation Kit (TaKaRa, Dalian, China). The concentration and quality of RNA was verified using a spectrophotometer and $1 \%$ agarose gel electrophoresis, respectively. Reverse transcription was performed with $1 \mu \mathrm{g}$ of total RNA using the PrimeScript ${ }^{\mathrm{TM}}$ RT Reagent Kit with gDNA Eraser (Perfect Real Time) (TaKaRa, Dalian, China). Genomic DNA was isolated from 20 pre-diapausing larvae with the Biospin Insect Genomic DNA Extraction Kit according to the manufacturer's instructions (Bioer Technology Co., Ltd., Hangzhou, China).

\subsection{Cloning of SmHsp17.4 and SmHsp20.3}

Based on annotated Hsp17.4 and Hsp20.3 sequences from the transcriptome database of $S$. mosellana larvae, gene-specific primers (Table 1) were designed to amplify cDNA end sequences with 3'-Full RACE (rapid amplification of cDNA ends) Core Set with PrimeScript ${ }^{\mathrm{TM}}$ RTase and 5'-Full RACE Kit with TAP (TaKaRa, Dalian, China). Nested PCRs were conducted with the following program: $94^{\circ} \mathrm{C}$ for $3 \mathrm{~min}$, followed by four cycles of $94{ }^{\circ} \mathrm{C}$ for $30 \mathrm{~s}, 60^{\circ} \mathrm{C}-58^{\circ} \mathrm{C}$ for $30 \mathrm{~s}$, and $72{ }^{\circ} \mathrm{C}$ for $90 \mathrm{~s}$ with a decrease of annealing temperature by $2{ }^{\circ} \mathrm{C}$ per two cycles; then 32 cycles of $94{ }^{\circ} \mathrm{C}$ for $30 \mathrm{~s}, 56{ }^{\circ} \mathrm{C}$ for $30 \mathrm{~s}, 72{ }^{\circ} \mathrm{C}$ for $90 \mathrm{~s}$, and $72^{\circ} \mathrm{C}$ for $10 \mathrm{~min}$. PCR products were confirmed by $1 \%$ agarose gel, purified using a gel extraction kit (Tiangen, Beijing, China), ligated into $\mathrm{pMD}^{\mathrm{TM}}$-19T vector (TaKaRa, Dalian, China), and then transformed into Escherichia coli DH5 $\alpha$-competent cells (Tiangen, Beijing, China) for sequencing analysis. Full-length cDNAs were subsequently PCR amplified using primers shown in Table 1 and Taq MasterMix (CWBio, Beijing, China).The amplification conditions were as follows: $95^{\circ} \mathrm{C}$ for $3 \mathrm{~min}$, followed by 4 cycles at $95^{\circ} \mathrm{C}$ for $40 \mathrm{~s}, 56-54{ }^{\circ} \mathrm{C}$ for $50 \mathrm{~s}$, and $72{ }^{\circ} \mathrm{C}$ for $2 \mathrm{~min}$ with a decrease of annealing temperature by $2{ }^{\circ} \mathrm{C}$ per two cycles; then 32 cycles at $95{ }^{\circ} \mathrm{C}$ for $40 \mathrm{~s}, 52{ }^{\circ} \mathrm{C}$ for $50 \mathrm{~s}, 72{ }^{\circ} \mathrm{C}$ for $2 \mathrm{~min}$, and $72{ }^{\circ} \mathrm{C}$ for $10 \mathrm{~min}$. PCR products were gel-purified, cloned, and sequenced. Genomic DNAs for Hsp17.4 and Hsp20.3 were also obtained by PCR using total DNA as the template and the sequence confirmed as above. 
Table 1. Primer sequences used in this study.

\begin{tabular}{crc}
\hline Primer Name & Sequence (5' to $^{\prime}$ ) & Purpose \\
\hline Hsp17.4-5'-outer & CTTGTTTCTCTTCGTGTTTGGCATG & \\
Hsp17.4-5'-inner & GTGACGCTTCGAAACCATCCTTG & \multirow{2}{*}{ ' RACE } \\
Hsp20.3-5'-outer & GATCGCAAAGCTGGATAATCGGTTG & \\
Hsp20.3-5'-inner & CGTCAAAAATGTGTGGCAATAGAGAC & \\
\hline Hsp17.4-3'-outer & CTACTCTCTCATCTGATGGTGTTCTCTC & \multirow{2}{*}{ ' RACE } \\
Hsp17.4-3'-inner & CAGAGCATCAAGAGCAACGAGGAG & \\
Hsp20.3-3'-outer & CAAACGGGACCAGCTCACTTGAATG & \\
Hsp20.3-3'-inner & AGCAACGAAGAAGTGAAAGACGAAG & Full-length cDNA \\
\hline Hsp17.4-F1 & AGTCGAATCTAAAGCATTCC & validation and gDNA \\
Hsp17.4-R1 & GGTCCTTTATATTGATTGAAATTTAC \\
Hsp20.3-F1 & TTATACGAATCGTTAACGAAAC & Prokaryotic \\
Hsp20.3-R1 & AATGAATTTCAAAATTCGCTCTTAG & expression \\
\hline Hsp17.4-F2 & CGGGATCCATGTCGTTGATTCCATTCC (BamHI) & \\
Hsp17.4-R2 & CCCAAGCTTGGGTTACTTTCCCTCTTTTTC (HindIII) & \\
Hsp20.3-F2 & CGGGATCCATGTCTCTATTGCCACACA (BamHI) & \\
Hsp20.3-R2 & CCCAAGCTTGGGTTATTTTCTTCGTCTTTC (HindIII) & \\
\hline Hsp17.4-q-F & GAGCACGGTTACATTTCGC & qPCR \\
Hsp17.4-q-R & CTCCTCGTTGCTCTTGATGCTCTGTTTGACT & \\
Hsp20.3-q-F & AAGCCGTCCTTGCCCATTT & \\
Hsp20.3-q-R & ATTATCGCTTGACTGGTGG & \\
GAPDH-q-F & CCATCAAAGCAAGCAAGA & \\
GAPDH-q-R & CAGCACGGAGCACAAGAC & \\
\hline
\end{tabular}

Restriction sites are underlined.

\subsection{Sequence Analysis and Phylogenetic Tree Construction}

The open reading frame (ORF) was analyzed using ORF finder (http: / / www.ncbi.nlm. nih.gov/gorf/gorf.html). Protein molecular weight and isoelectric point were deduced using the Compute $\mathrm{pI} / \mathrm{Mw}$ tool (http:/ / web.expasy.org/protparam/). Functional domains were identified using a conserved domain search tool (http:/ / www.ncbi.nlm.nih.gov/ Structure/cdd/wrpsb.cgi). Multiple sequence alignment was performed using the DNAMAN software (Lynnon Corporation, Pointe-Claire, QC, Canada). Secondary and threedimensional (3D) structures were predicted using ESPrigt (http:/ / espript.ibcp.fr /ESPript/ cgi-bin/ESPript.cgi) and SWISS-MODEL Server (https:/ /www.swissmodel.expasy.org/), respectively. Images were visualized using the PyMOL Molecular Graphics System (Version 1.3, Schrödinger, LLC, New York, NY, USA). The GMQE (Global Model Quality Estimation) and QMEAN (Qualitative Model Energy Analysis) values of the homology model were, respectively, 0.75 and -0.59 for SmHsp17.4, and 0.79 and 0.42 for SmHsp20.3. The phylogenetic tree was constructed using the neighbor-joining method in MEGA 6.0 software [43], and parameters included complete deletion, 1000 replicates for bootstrap analysis, and p-distance model.

\subsection{Heat/Cold Shock Treatments}

S. mosellana cocooned larvae are mainly located $3-10 \mathrm{~cm}$ below the soil surface [44]. Temperatures in this soil layer are around $32{ }^{\circ} \mathrm{C}$ (highest) in summer and around $0{ }^{\circ} \mathrm{C}$ (lowest) in winter in Yangling $\left(34^{\circ} 16^{\prime} \mathrm{N}, 108^{\circ} 4^{\prime} \mathrm{E}\right)$, Shaanxi province, China. However, agricultural practices like tillage could occasionally expose the diapausing insects to extreme temperatures as high as $50^{\circ} \mathrm{C}$ in summers or as low as $-15^{\circ} \mathrm{C}$ in winters. To elucidate the potential function of SmHsp17.4 and SmHsp20.3 under such conditions, over-summering and over-wintering larvae were further treated with heat or cold shock. Briefly, freshly cocooned larvae collected in August were put into $1.5 \mathrm{~mL}$ cryogenic vials, and then submerged in water bathes at various high temperatures $\left(35-50{ }^{\circ} \mathrm{C}\right)$ for $1 \mathrm{~h}$, and at $35^{\circ} \mathrm{C}$ for various time periods (0-120 min). Samples from a $60 \mathrm{~min}$ heat shock at $35^{\circ} \mathrm{C}$ were also subjected to a different recovery time (30-360 $\mathrm{min}$ ) at room temperature. Similarly, vials containing December-cocooned larvae were placed in incubators with temperature controlled at various low temperature $\left(0-15^{\circ} \mathrm{C}\right)$ for $1 \mathrm{~h}$, and at $-10^{\circ} \mathrm{C}$ for various time periods $(0-120 \mathrm{~min})$. Samples from a $60 \mathrm{~min}$ cold shock at $-10^{\circ} \mathrm{C}$ also experienced a 
different recovery time (30-360 $\mathrm{min}$ ) at room temperature. Larvae collected prior to temperature treatments acted as the untreated control. After treatment at each time point, larvae were frozen immediately in liquid nitrogen and stored at $-80{ }^{\circ} \mathrm{C}$ for reverse-transcription quantitative PCR (RT-qPCR) analysis. Each treatment was conducted at least three times with 20 individuals per replicate.

\subsection{E Treatment}

To ascertain whether 20-hydroxyecdysone (20E) affected expression of SmHsp17.4 and SmHsp20.3 in diapausing larvae, cocooned larvae freshly collected in October were abdomen-injected with $23 \mathrm{~nL} 20 \mathrm{E}$ (Sigma-Aldrich, St. Louis, MO, USA) at concentrations of 0.1-0.4 pg/nL diluted in 50\% ethanol using a Nanoject II Auto-Nanoliter Injector (Drummond Scientific Company, Broomall, PA, USA). Insects at this stage were selected because they showed low expression of SmHsp17.4 and SmHsp20.3 (see Results). Injection doses were comparable to endogenous 20E levels reported in larvae of this species [45]. Injected larvae were placed in petri dishes with moist filter papers and continuously incubated for 3,6 , or $12 \mathrm{~h}$ at $25^{\circ} \mathrm{C}$ in the artificial climate incubator prior to being frozen in liquid nitrogen and stored in a $-80^{\circ} \mathrm{C}$ freezer for RNA isolation later on. Control insects were treated with the same volume of $50 \%$ ethanol. Each treatment was repeated at least three times with a minimum of 20 individuals per replicate.

\subsection{Expression Analysis Using RT-qPCR}

To determine the expression profile of SmHsp17.4 and SmHsp20.3 in response to diapause, extreme heat/cold stresses, and 20E treatment, total RNA of each sample was isolated and cDNAs were synthesized from $1.0 \mu \mathrm{g}$ total RNA as described above. Three replicates were conducted for each sample.

RT-qPCR was performed using the SYBR Premix EX Taq ${ }^{\mathrm{TM}}$ II kit (Tli RNaseH Plus) (Takara, Dalian, China) on the QuantStudio ${ }^{\circledR} 5$ real-time PCR system (Thermo Fisher Scientific, Waltham, MA, USA) under the following conditions: $95^{\circ} \mathrm{C}$ for $30 \mathrm{~s}$, then 40 cycles of $95{ }^{\circ} \mathrm{C}$ for $5 \mathrm{~s}, 60{ }^{\circ} \mathrm{C}$ for $30 \mathrm{~s}$, and $72{ }^{\circ} \mathrm{C}$ for $30 \mathrm{~s}$. The reference gene gapdh (GenBank number: KR733066) was used as the experimental control. The result showed that the amplification efficiencies for $g a p d h, S m H s p 17.4$, and SmHsp20.3 were respectively 103\%, 96\%, and $97 \%$, which were automatically calculated by a real-time PCR system. The transcript abundance of each SmHsp gene (for primers, see Table 1) was normalized to that of the reference gene, and the relative expression was calculated with the $2^{-\Delta \Delta C T}$ method [46]. Data were shown as means \pm SE (standard error). Differences among treatments was analyzed by one-way analysis of variance followed by Duncan's multiple range tests $(p<0.05)$. The relationship between 20E levels and $s H s p$ expression was analyzed using correlation analysis.

\subsection{Recombinant Protein Expression and Purification}

To construct SmHsp17.4 and SmHsp20.3 expression vectors, specific primers with restriction sites designed at their $5^{\prime}$ ends (BamHI in the sense primer and HindIII in the anti-sense primer) were used to amplify the coding sequences of SmHsp17.4 and SmHsp20.3 (Table 1). The products, confirmed by sequencing, were digested and inserted into the linearized pET28a (+) expression vector (Novagen, Madison, WI, USA) restricted by the same restriction enzymes. The construct containing SmHsp17.4 gene was transformed into E. coli Rosetta cells, whereas the SmHsp20.3 construct was transformed into E. coli BL21 cells (Tiangen, Beijing, China). A single recombinant colony was grown overnight at $37^{\circ} \mathrm{C}$ in $5 \mathrm{~mL}$ of Luria-Bertani (LB) medium with $100 \mu \mathrm{g} / \mathrm{mL}$ kanamycin. The culture was then diluted 100-fold with fresh LB medium $(500 \mathrm{~mL})$ and continuously incubated at $37^{\circ} \mathrm{C}$ until the optical density at $600 \mathrm{~nm}\left(\mathrm{OD}_{600}\right)$ reached $0.6-0.8$, when isopropyl $\beta$-D1-thiogalactopyranoside (IPTG) was added to a final concentration of $0.5 \mathrm{mM}$, followed by a further incubation with shaking for $5 \mathrm{~h}$ at $37^{\circ} \mathrm{C}$. Cells were harvested by centrifugation at $8000 \times g$ for $10 \mathrm{~min}$, re-suspended in the lysis buffer $(20 \mathrm{mM}$ Tris- $\mathrm{HCl} \mathrm{pH} 7.4$, 
$0.5 \mathrm{mM}$ phenylmethanesulfonyl fluoride), lysed using $0.4 \mathrm{mg} / \mathrm{mL}$ lysozyme and repeated freeze-thaw cycles in liquid nitrogen, and then centrifuged again at 12,000 $\times \mathrm{g}$ for $30 \mathrm{~min}$. Recombinant protein expression was examined in supernatant and pellet with $15 \%$ sodium dodecyl sulfate polyacrylamide gel electrophoresis (SDS-PAGE).

Insoluble SmHsp17.4 was denatured with $8 \mathrm{M}$ urea and refolded by following a previously-described procedure [47]. The solubilized SmHsp17.4 and soluble SmHsp20.3 were purified using the Ni-NTA His-Bind Resin column (7sea Pharmatech Co., Shanghai, China), and examined by $15 \%$ SDS-PAGE.

\subsection{Thermal Aggregation Assays}

To determine if recombinant SmHsp17.4 and SmHsp20.3 could suppress thermal aggregation of pig heart mitochondrial malate dehydrogenase (MDH), $0.5 \mu \mathrm{M} \mathrm{MDH}$ in PBS buffer was incubated at $43^{\circ} \mathrm{C}$ in an Infinite M1000 PRO microplate reader (Tecan Group Ltd., Männedorf, Switzerland), alone or in the presence of SmHsp17.4, SmHsp20.3, bovine serum albumin (BSA, the non-chaperone control) in a molar ratio of 1:1. Absorbance at $360 \mathrm{~nm}$ was measured every $10 \mathrm{~min}$ for $70 \mathrm{~min}$ [48]. Three replications were conducted for each sample.

\section{Results}

3.1. Characterization of SmHsp17.4 and SmHsp20.3

The full-length cDNA of S. mosellana Hsp17.4 (SmHsp17.4) obtained by RACE-PCR was 773-bp (Figure S1, GenBank accession no: MK714040), which contained a 144-bp 5' untranslated region (UTR), a 456-bp open reading frame (ORF), and a 173-bp $3^{\prime} \mathrm{UTR}$. The predicted ORF encoded a protein of 151 amino acids with an estimated molecular weight of $17.4 \mathrm{kDa}$ and an isoelectric point (pI) of 6.87. The cDNA sequence of $S m H s p 20.3$ was $803 \mathrm{bp}$ long (Figure S1, GenBank accession no: MK714041), and contained a 81-bp 5' UTR, a 543-bp ORF, and a 179-bp $3^{\prime}$ UTR. The ORF encoded a protein of 180 amino acids with molecular weight of $20.3 \mathrm{kDa}$ and a $\mathrm{pI}$ of 5.80. Comparison between cDNA and gDNA sequences revealed that $\mathrm{SmHsp} 17.4$ contained one $85 \mathrm{bp}$ intron at position $108 \mathrm{bp}$ downstream of start codon ATG (Figure S2), while SmHsp20.3 had none.

Searching for conserved domains identified the $\alpha$-crystallin domain in both SmHsps79 amino acid residues (42-120) in SmHsp17.4 and 78 residues (67-144) in SmHsp20.3. The I/VXI/V motif was also present in the C-terminal regions (a.a. 129-131 in SmHsp17.4 and a.a. 157-159 in SmHsp20.3) (Figure 1 and Figure S1). In addition, 21 glutamine and glutamic acid residues, known to promote protein stability under elevated temperatures by providing additional electrostatic force [49], were detected. Only one cysteine residue (C-118) was found in SmHsp17.4 and three in SmHsp20.3 (C-15, C-20, and C-74), consistent with the study of Fu et al. (2003) [50] who concluded that cysteine residues were rare in the sequences of molecular chaperones compared to other protein families.

Sequence alignment demonstrated that SmHsp17.4 exhibited the highest amino acid sequence identity (57\%) to Bactrocera dorsalis Hsp18.4 (ARQ14797.1), 49-55\% identity to B. dorsalis Hsp20 (AEJ88463.1), Anopheles gambiae Hsp23.4 (XP_315550.4), and Hsp23 from Ceratitis capitate (XP_004523813.1), Musca domestica (XP_005190092.1), and Lucilia cuprina (XP_023304392.1). SmHsp20.3 was 59\% identical to Hsp23 from C. capitate and L. cuprina, and $52-56 \%$ identical to B. dorsalis Hsp18.4, B. dorsalis Hsp20, A. gambiae Hsp23.4, and M. domestica Hsp23. The two SmHsps were 43\% identical (Figure 1). The phylogenetic analysis revealed that different sHsps of the same insect species tended to cluster together, and the two SmHsps were most closely related to sHsps from the Nematocera (A. gambiae) in Diptera (Figure 2). 


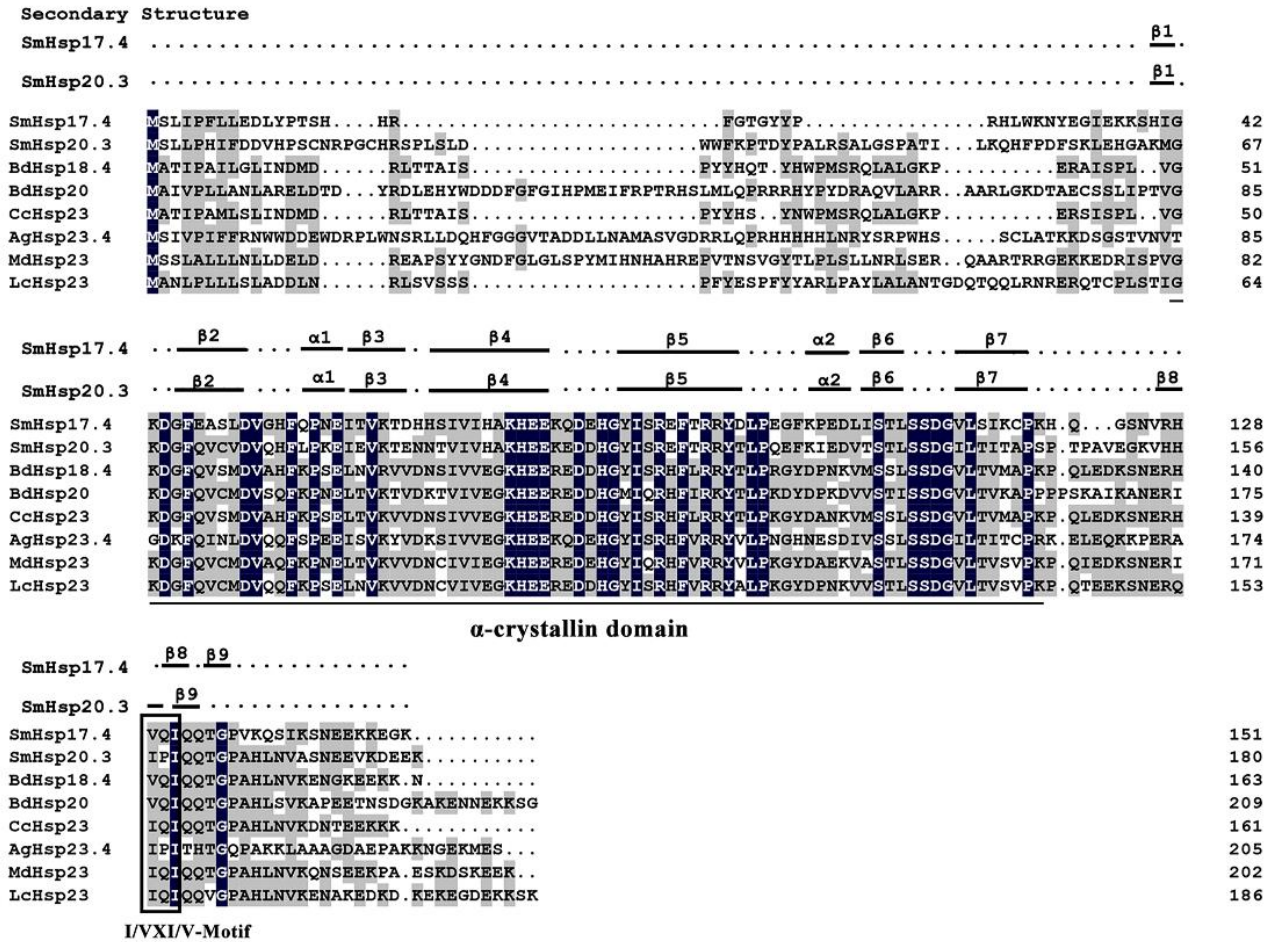

Figure 1. Amino acid sequence alignment of SmHsp17.4, SmHsp20.3, and small heat shock proteins (sHsps) from other insect species. Identical and similar residues are shaded black and grey, respectively. The $\alpha$-crystallin domain is underlined and the I/VXI/V motif is boxed. Putative secondary structures are labeled above sequences as $\alpha$ ( $\alpha$-helices), $\beta$ ( $\beta$-strands), and dotted lines (coils), respectively. Sm, Sitodiplosis mosellana; Bd, Bactrocera dorsalis; Cc, Ceratitis capitata; Ag, Anopheles gambiae; Md, Musca domestica; and Lc, Lucilia cuprina.

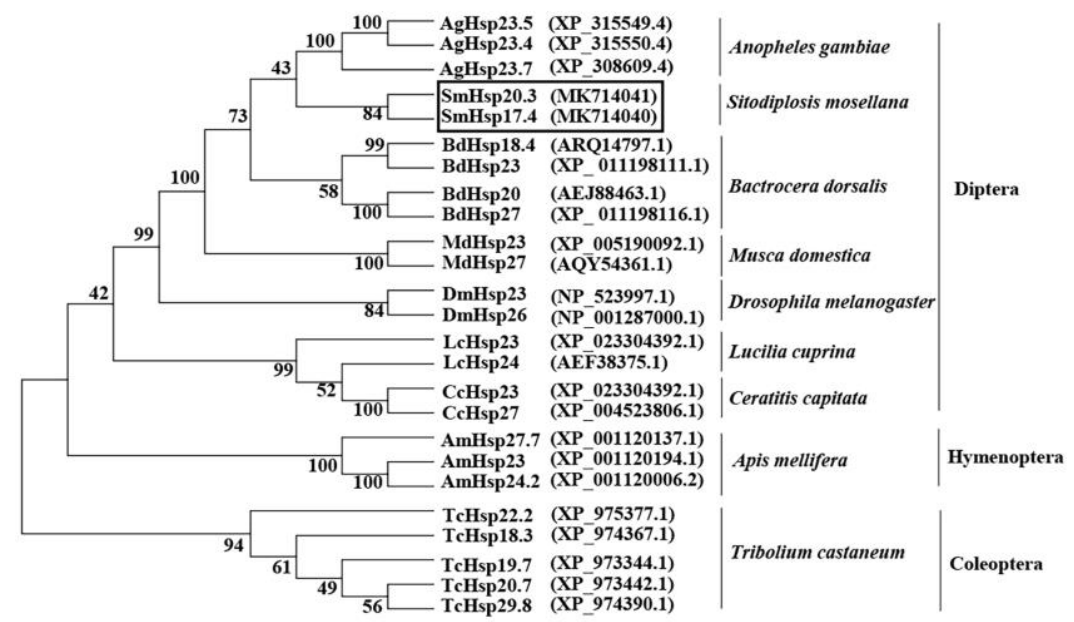

Figure 2. Phylogenetic relationship of SmHsp17.4 and SmHsp20.3 (boxed) as well as sHsps from other insects. The phylogenetic tree was built by the neighbor-joining method using MEGA 6.0 with 1000 bootstrap replications.

Analysis of the secondary structure revealed six $\beta$-strands and two $\alpha$-helixes in the $\alpha$-crystallin domain of the SmHsps (Figure 1). The predicted three-dimensional structure was generated based on the zebrafish (Danio rerio) homolog (PDB ID: 3n3e.1A), presumably the best template as it shared $47.4 \%$ and $49.4 \%$ sequence identity with SmHsp17.4 and SmHsp20.3, respectively. For both SmHsps, the conserved $\alpha$-crystallin domain existed in a dimeric structure. In each monomer, six $\beta$-strands were folded into a compact $\beta$-sandwich composed of two antiparallel $\beta$-sheets (Figure 3 ). 


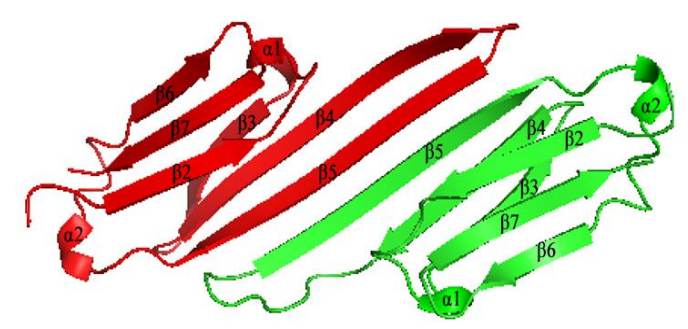

Figure 3. Predicted $\alpha$-crystallin domain dimeric structure of SmHsp17.4 and SmHsp20.3. The SWISS MODEL server was used to simulate three-dimensional structure based on the defined zebrafish (Danio rerio) homolog (PDB ID: 3n3e.1A). Image was visualized using PyMOL software. Individual monomers are marked red and green.

\subsection{Expression of SmHsp17.4 and SmHsp20.3 during Diapause}

Transcript profiles of SmHsp17.4 and SmHsp20.3 during diapause, including prediapause (May), diapause (June-November), post-diapause quiescence (December-next February), and post-diapause development (March of the next year) were determined by RTqPCR. Expression of $S m H s p 17.4$ decreased after the initiation of diapause (June), stayed low during diapause maintenance (June to October), but significantly increased in November, a transition time from diapause to post-diapause quiescence, and peaked in December and January. Expression distinctly decreased thereafter, and returned to the early-diapause level after development resumed (Figure 4A). In contrast, expression of SmHsp20.3 did not change when S. mosellana entered diapause (June), but peaked in July and August and the early-to-mid period of post-diapause quiescence (December and January) (Figure 4B). Expression was relatively low at the post-diapause developmental stage.
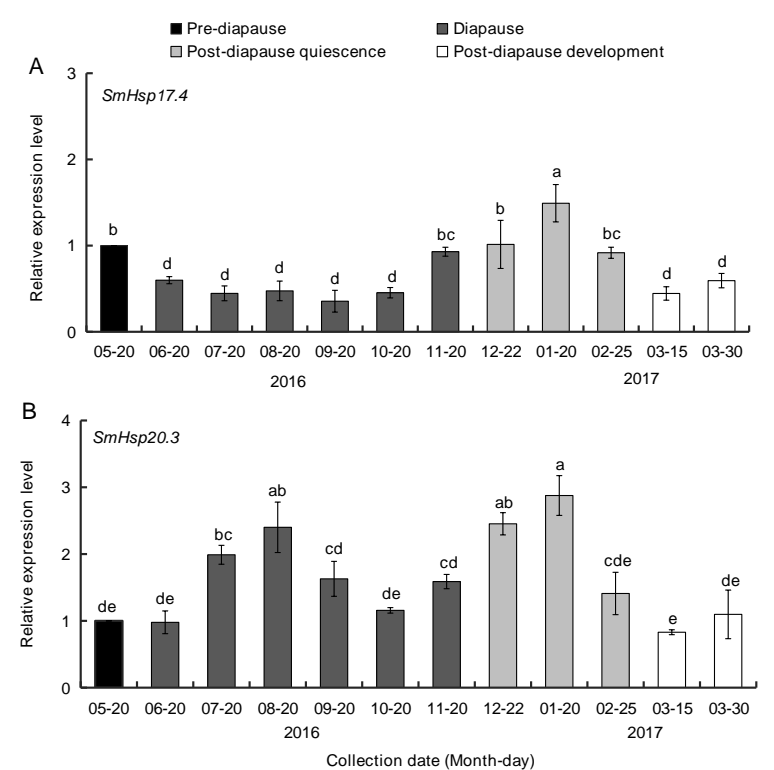

Figure 4. Expression profiles of SmHsp17.4 (A) and SmHsp20.3 (B) in pre-diapausing, diapausing, and post-diapausing larvae by RT-qPCR. The expression level of each tested stage was relative to that of the pre-diapause stage, which was arbitrarily set at 1 . Bars represent the means $\pm \mathrm{SE}$. Different letters above bars indicated significant difference by Duncan's multiple range test $(p<0.05)$.

\subsection{Effect of Temperature Extremes on SmHsp Expression during Diapause}

When over-summering diapausing larvae were treated with various temperatures higher than the typical habitat temperature in the hottest period of the summer for $60 \mathrm{~min}$, expression of $\mathrm{SmHsp} 17.4$ and $\mathrm{SmHsp} 20.3$ was significantly higher at the temperature ranging from 35 to $40{ }^{\circ} \mathrm{C}$ than the untreated control; a 4.0-fold increase for SmHsp17.4 and a 9.4-fold 
for $S m H s p 20.3$ were observed at $35^{\circ} \mathrm{C}$, but such up-regulation was not seen in the 45 to $50{ }^{\circ} \mathrm{C}$ range (Figure $\left.5 \mathrm{~A}, \mathrm{~B}\right)$.
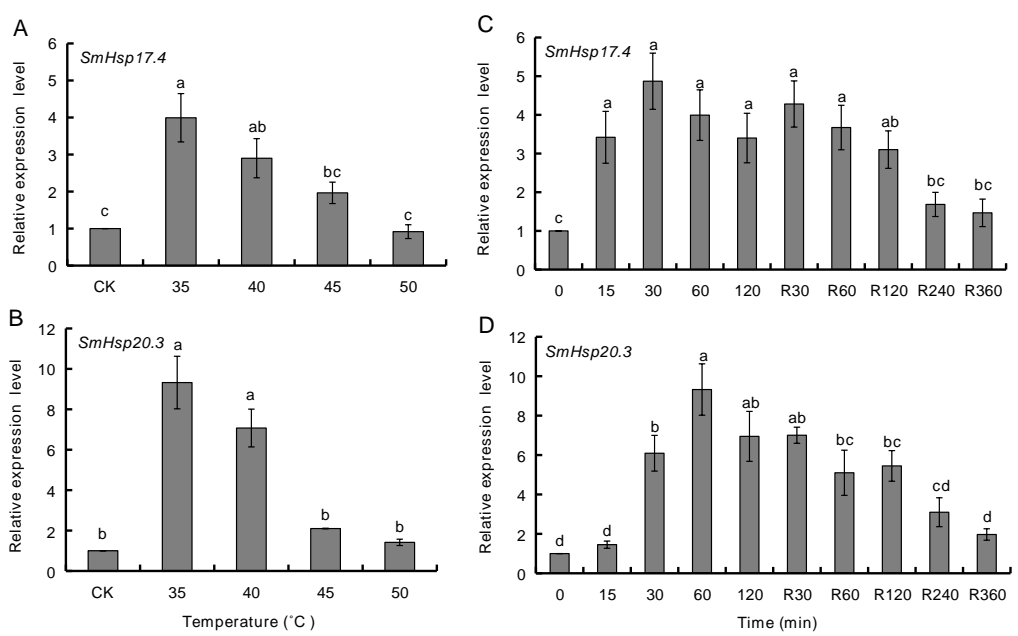

Figure 5. Effect of high temperature extremes on expression of SmHsp17.4 and SmHsp20.3 in oversummering diapausing larvae. (A,B) Exposure to various high temperature $\left(35-50^{\circ} \mathrm{C}\right)$ for $1 \mathrm{~h} .(\mathbf{C}, \mathbf{D})$ Exposure to $35^{\circ} \mathrm{C}$ for various time periods $\left(0-120 \mathrm{~min}\right.$, left side), as well as a $60 \mathrm{~min}$ exposure to $35^{\circ} \mathrm{C}$ followed by different recovery time (R30-360 min, right side). Expression level of each treatment was relative to that of the untreated control (CK, $0 \mathrm{~min}$ ), which was arbitrarily set at 1 . Bars represent the means $\pm \mathrm{SE}$. The different letters above the columns indicate significant difference by Duncan's multiple range test $(p<0.05)$.

We also examined the response of both genes to heat shock duration at $35^{\circ} \mathrm{C}$ as well as to recovery time at room temperature from $60 \mathrm{~min}$ exposure to $35^{\circ} \mathrm{C}$ (Figure 5C,D). SmHsp17.4 expression significantly increased upon 15 min of heat shock, remained at similar levels as treatment duration was extended $(120 \mathrm{~min})$ and during the first $60 \mathrm{~min}$ of recovery, before declining. Expression of SmHsp20.3 significantly increased at $30 \mathrm{~min}$ of heat shock, peaked at $60 \mathrm{~min}$, and gradually declined after $30 \mathrm{~min}$ of recovery. After recovering for $240 \mathrm{~min}$, expression of both genes returned to the control levels.

Likewise, SmHsp17.4 and SmHsp20.3 expression were determined in over-wintering larvae subjected to further cold-shock treatments for $1 \mathrm{~h}$ at various low temperatures (Figure $6 \mathrm{~A}, \mathrm{~B}$ ). $\operatorname{SmHsp} 17.4$ was significantly induced at $-5^{\circ} \mathrm{C},-10^{\circ} \mathrm{C}$, and $-15^{\circ} \mathrm{C}$, with the maximum expression level at $-10^{\circ} \mathrm{C}$ (approximately 8.4-fold). Up-regulation of $S m H s p 20.3$, however, was observed only at $-10^{\circ} \mathrm{C}$ (3.6-fold).

Cold shock duration and different subsequent recovery time had different effects on the two genes (Figure 6C,D). When exposed to $-10{ }^{\circ} \mathrm{C}$, SmHsp17.4 transcripts rapidly increased at $15 \mathrm{~min}$, and reached maximum at $60 \mathrm{~min}$. SmHsp20.3, however, responded at 30-60 min cold treatment, with the expression peaked at $30 \mathrm{~min}$. During the recovery period following a $60 \mathrm{~min}$ exposure at $-10{ }^{\circ} \mathrm{C}, \mathrm{SmHsp} 17.4$ remained high at the first $120 \mathrm{~min}$ and gradually dropped thereafter whereas SmHsp20.3 rapidly decreased to the minimal level. 

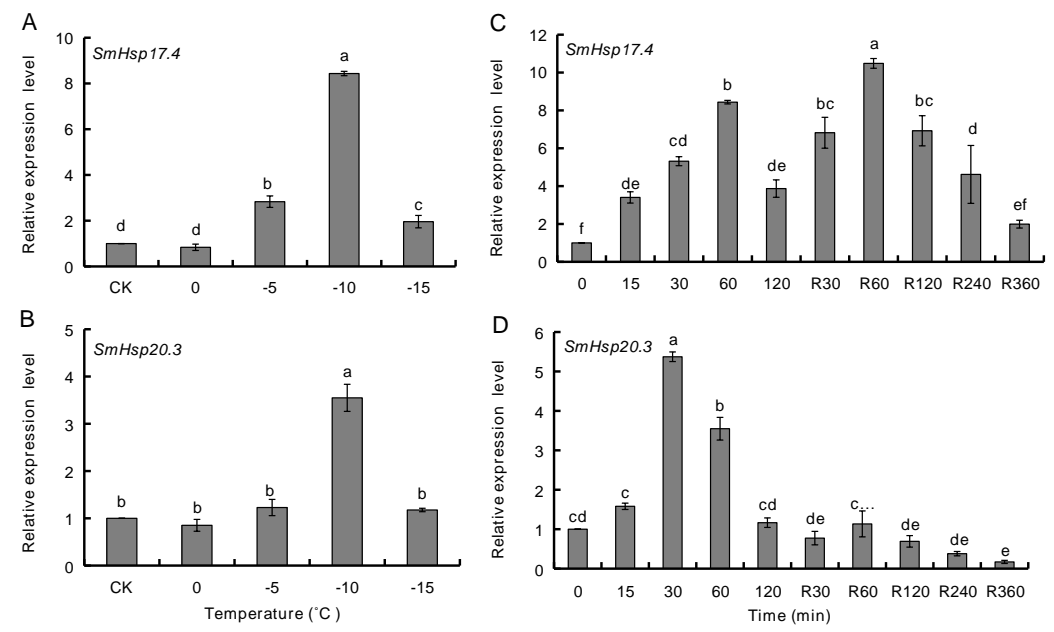

Figure 6. Effect of low temperature extremes on expression of SmHsp17.4 and SmHsp20.3 in overwintering diapausing larvae. (A,B) Exposure to various low temperature $\left(0-15^{\circ} \mathrm{C}\right)$ for $1 \mathrm{~h}$. $(\mathbf{C}, \mathbf{D})$ Exposure to $-10^{\circ} \mathrm{C}$ for various time periods (0-120 min, left side), as well as a $60 \mathrm{~min}$ exposure to $-10{ }^{\circ} \mathrm{C}$ followed by different recovery time (R30-360 min, right side). Expression level of each treatment was relative to that of the untreated control $(\mathrm{CK}, 0 \mathrm{~min})$, which was arbitrarily set at 1 . Bars represent the means \pm SE. The different letters above the columns indicated significant difference by Duncan's multiple range test $(p<0.05)$.

\subsection{E Regulation of SmHsp17.4 and SmHsp20.3 during Diapause}

Different expression patterns of two SmHsps were observed when diapausing larvae (collected in October) were subjected to 20E treatment. SmHsp20.3 did not change, while SmHsp 17.4 transcripts were greatly induced at $6 \mathrm{~h}$ post treatment, and showed a strong positive relationship with the $20 \mathrm{E}$ concentration $(r=0.932, p<0.01)$. Some residual effect was also observed at $12 \mathrm{~h}$ after treatment $(r=0.835, p=0.001)$. No notable change was observed $3 \mathrm{~h}$ after 20E injection at any concentration examined (Figure 7).

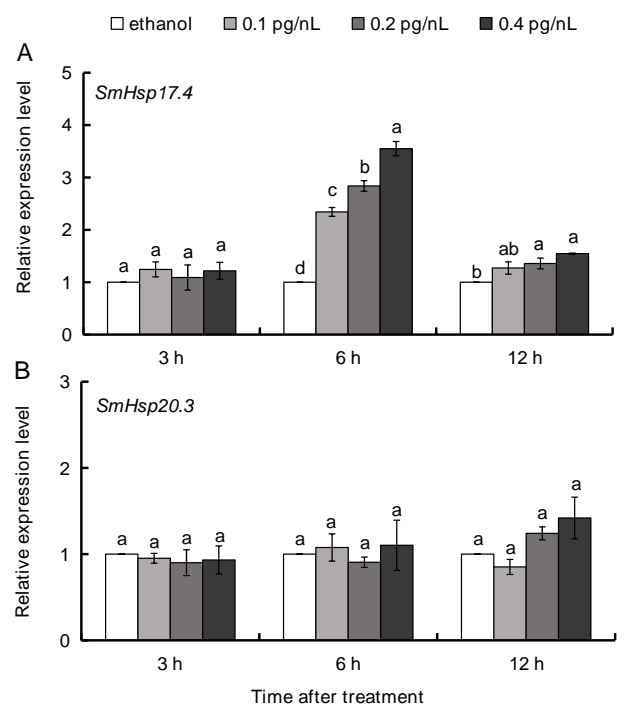

Figure 7. Effect of 20-hydroxyecdysone (20E) on expression of $S m H s p 17.4$ (A) and SmHsp20.3 (B) in diapausing larvae collected in October. Transcript levels were determined by RT-qPCR at 3, 6, and $12 \mathrm{~h}$ after $20 \mathrm{E}(0-0.4 \mathrm{pg} / \mathrm{nL})$ injection. Expression level of each treatment was relative to that of $50 \%$ ethanol injection (the control), which was arbitrarily set at 1 . Bars represent the means \pm SE. The different letters above the columns within each group indicated significant difference by Duncan's multiple range test $(p<0.05)$. 


\subsection{Chaperone Activity of Recombinant SmHsp17.4 and SmHsp20.3}

After IPTG induction, SmHsp17.4 was present mainly in inclusion bodies whereas SmHsp20.3 was expressed as a soluble protein (Figure 8). Successful refolding and purification were demonstrated by SDS-PAGE ( $22 \mathrm{kD}$ and $25 \mathrm{kD}$, including His-tag, respectively). The concentrations of the purified proteins were $637 \mu \mathrm{g} / \mathrm{mL}$ for SmHsp17.4 and $84 \mu \mathrm{g} / \mathrm{mL}$ for SmHsp20.3.
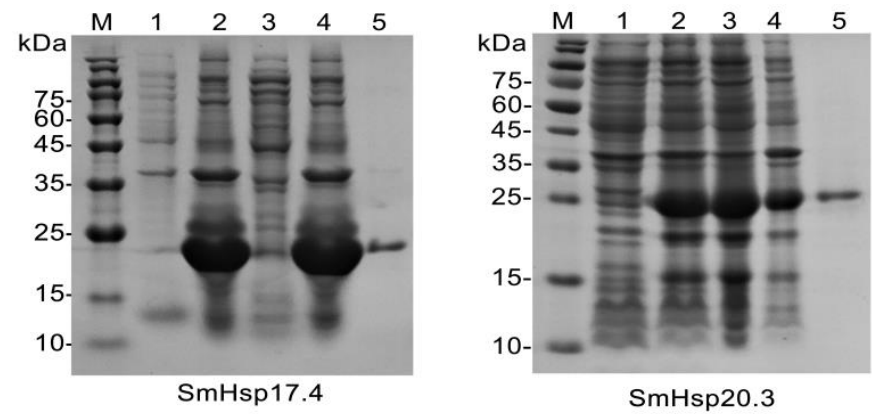

Figure 8. Expression and purification of recombinant SmHsp proteins by SDS-PAGE. M, molecular weight marker; lanes 1 and 2, un-induced and induced E. coli with pET28a (+)/SmHsps, respectively; lanes 3 and 4, supernatant and inclusion body of pET28a (+)/SmHsps after IPTG induction, respectively; lane 5, Ni-NTA affinity-purified pET28a (+)/SmHsp proteins.

In the thermal aggregation assays (Figure 9), mitochondrial malate dehydrogenase (MDH) aggregated when the solution was incubated at $43{ }^{\circ} \mathrm{C}$ in the absence of the SmHsps, as indicated by the remarkable increase in absorbance at $360 \mathrm{~nm}$. This heat-induced aggregation of MDH, however, did not occur in the presence of SmHsp17.4 or SmHsp20.3, suggesting their significant molecular chaperone functionality. The non-chaperone BSA control not only failed to prevent heat-induced aggregation, but sped up this process as well.

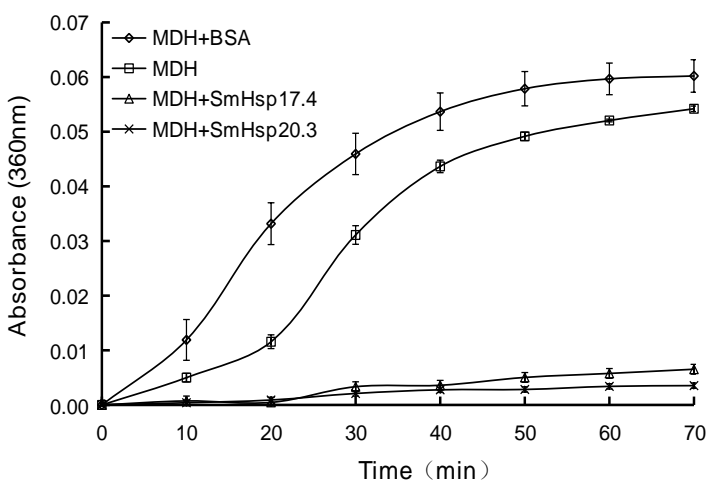

Figure 9. Molecular chaperone activity of SmHsp17.4 and SmHsp20.3. To perform mitochondrial malate dehydrogenase (MDH) thermal aggregation assays, $\mathrm{MDH}(0.5 \mu \mathrm{M})$ was incubated at $43^{\circ} \mathrm{C}$ in the absence and in the presence of SmHsp17.4, SmHsp20.3, or bovine serum albumin (BSA, control) in a molar ratio 1:1. Aggregation of $\mathrm{MDH}$ was reflected by the absorbance at $360 \mathrm{~nm}$. Data were obtained from three independent experiments and were shown as the means $\pm \mathrm{SE}$.

\section{Discussion}

After characterization of several high-molecular-weight heat shock proteins, Hsp90, Hsp70/Hsc70, and Hsp40 in S. mosellana [42,51], in the current study, we identified two members of the sHsps from this species, SmHsp17.4 and SmHsp20.3. Sequence alignment revealed conserved motifs- $\alpha$-crystallin domain that is essential for the molecular chaperone function, as well as the I/VXI/V motif that acts as an anchor in the oligomerization process [52]. Like most sHsps, $\alpha$-crystallin domain of SmHsp17.4 and SmHsp20.3 is rich 
in $\beta$-strands organized into the $\beta$-sheet (Figures 1 and 3 ), which is the basic structural unit for sHsps and helps facilitate dimer formation and subsequent oligomerization of sHsps $[10,14,19]$. Phylogenetic analysis suggested that different sHsps of the same species are clustered together. This is in agreement with a previous study covering a great number of sHsps from fungi, insects, plants, and vertebrates [53], suggesting that sHsps may have evolved by gene duplication after species divergence.

Given that a specific sHsp member may have a unique response and function in coping with stresses during insect diapause [24-29], we profiled expression of the newly-cloned SmHsp genes. We used the $S$. mosellana population that was exposed to natural conditions, rather than that raised under lab conditions, as in most molecular studies related to diapause. Our study with field-collected S. mosellana indicated that SmHsp17.4 was down-regulated upon entry into diapause, but winter low temperature, a necessary factor to terminate diapause [41], greatly elevated expression (Figure 4A). Therefore, SmHsp17.4 might be involved in the initiation and termination of diapause. Because SmHsp17.4 was upregulated at an early stage in the transition from diapause to post-diapause quiescence, a stage morphologically indistinguishable from diapause, it could serve as a useful biomarker to predict diapause termination. Such a biomarker role has also been proposed for S. nonagrioides Hsp20.8 [27] that displays a similar expression pattern to SmHsp17.4 during diapause.

Larval diapause is known to be directly regulated by juvenile hormone and the steroid hormone ecdysone (mainly 20E) [54,55]. Interestingly, 20E titers in S. mosellana decline dramatically after entering diapause but significantly increase in December and January to levels higher than any other diapause periods [45]. Such a titer pattern coincides with the SmHsp17.4 expression profile. Moreover, SmHsp17.4 transcription in diapause larvae was inducible by 20E (Figure 7A), suggesting that ecdysone is responsible for transcriptional regulation of $S m H s p 17.4$ during this specific developmental stage. To our knowledge, this is the first report on $20 \mathrm{E}$ regulation of an sHsp gene during insect diapause despite many studies on such regulation during normal development [33-36].

SmHsp20.3 expression was not affected by entry into diapause and 20E, but was clearly induced by seasonally-high and -low temperatures (Figures $4 \mathrm{~B}$ and 7B), implying that SmHsp20.3 is likely involved in heat/cold stresses during S. mosellana diapause, but is unrelated to hormone regulation. SmHsp20.3 is intronless, and such sHsps are believed to be associated with responses to environmental stresses [2]. Conversely, sHsps with at least one intron, like SmHsp17.4, are mostly involved in metabolic processes [13]. Such an assumption may explain the higher induction of SmHsp20.3 than SmHsp17.4 by seasonal temperature changes.

More severely heat-stressed $\left(\geq 35^{\circ} \mathrm{C}\right)$ over-summering larvae or cold-stressed $\left(\leq-5{ }^{\circ} \mathrm{C}\right)$ over-wintering larvae rapidly elevated expression of the $S m H s p s$, but such induction did not last long (Figures 5 and 6). It is possible that SmHsps provide short protection when diapausing $S$. mosellana are exposed to thermal extremes on soil surface by agricultural practices like tillage [56,57]. Enhancing stress tolerance was also reflected by their chaperone activity evidenced by the thermal aggregation assays (Figure 9). Clearly, SmHsp17.4 was more responsive to cold stress and SmHsp20.3 was more sensitive to heat stress (Figures 4-6), implying that $S m H s p 17.4$ may be more prominent for cold tolerance and SmHsp20.3 for heat tolerance.

\section{Conclusions}

In summary, our results suggested that SmHsp17.4 and SmHsp20.3 genes may contribute to stress tolerance in $S$. mosellana, and that their higher expression in diapausing insects in hot or cold environments could protect $S$. mosellana from stress-induced injuries. Given its regulation by $20 \mathrm{E}, \mathrm{SmHsp} 17.4$ was also likely involved in the initiation and termination of the diapause process. Given that RNAi is not yet technically feasible for S. mosellana, technical improvement for in vivo functional analysis specific for this particular species is necessary to understand the molecular mechanism underlying diapause. 
Supplementary Materials: The following are available online https:/ / www.mdpi.com/2075-445 0/12/2/119/s1: Figure S1: Nucleotide and deduced amino acid sequences of SmHsp17.4 and SmHsp20.3. Start codons (ATG) and stop codons (TAA) are boxed. The $\alpha$-crystallin domain was shaded. I/VXI/V motif was indicated with oval. Figure S2: Genomic DNA sequence of SmHsp17.4. Start codon (ATG) and stop codon (TAA) were boxed. The intron was shaded.

Author Contributions: Conceptualization, W.C. and K.Z.-S.; methodology, J.Z. and Q.H.; investigation, J.Z. and Q.H.; formal analysis, J.Z., Q.H., G.Z., and W.C.; writing-original draft preparation, J.Z., Q.H., and W.C.; writing-review and editing, W.C and K.Z.-S. All authors have read and agreed to the published version of the manuscript.

Funding: This work was supported by the National Natural Science Foundation of China (31371933), the Key Research and Development Program of Shaanxi province, China (2020NY-059), and the National Key Research and Development Program of China (2018YFD0200402).

Institutional Review Board Statement: Not applicable.

Informed Consent Statement: Not applicable.

Data Availability Statement: The data supporting reported results are available in the Supplementary Materials of this article.

Conflicts of Interest: The authors declare no conflict of interest.

\section{References}

1. Shu, Y.H.; Du, Y.; Wang, J.W. Molecular characterization and expression patterns of Spodoptera litura heat shock protein 70/90, and their response to zinc stress. Comp. Biochem. Physiol. A Mol. Integr. Physiol. 2011, 158, 102-110. [CrossRef] [PubMed]

2. Zhang, Y.; Liu, Y.; Guo, X.; Li, Y.; Gao, H.; Guo, X.; Xu, B. sHsp22.6, an intronless small heat shock protein gene, is involved in stress defence and development in Apis cerana cerana. Insect Biochem. Mol. Biol. 2014, 53, 1-12. [CrossRef] [PubMed]

3. Cheng, W.; Lei, J.; Fox, C.W.; Johnston, J.S.; Zhu-Salzman, K. Comparison of life history and genetic properties of cowpea bruchid strains and their response to hypoxia. J. Insect Physiol. 2015, 75, 5-11. [CrossRef]

4. Tungjitwitayakul, J.; Tatun, N.; Vajarasathira, B.; Sakurai, S. Expression of Heat Shock Protein Genes in Different Developmental Stages and After Temperature Stress in the Maize Weevil (Coleoptera: Curculionidae). J. Econ. Entomol. 2015, 108, 1313-1323. [CrossRef]

5. García-Reina, A.; Rodríguez-García, M.J.; Ramis, G.; Galian, J. Real-time cell analysis and heat shock protein gene expression in the TcA Tribolium castaneum cell line in response to environmental stress conditions. Insect Sci. 2016, 24, 358-370. [CrossRef]

6. Feder, M.E.; Hofmann, G.E. Heat-Shock proteins, molecular chaperones and the stress response: Evolutionary and Ecological Physiology. Annu. Rev. Physiol. 1999, 61, 243-282. [CrossRef]

7. Arya, R.; Mallik, M.; Lakhotia, S.C. Heat shock genes-Integrating cell survival and death. J. Biosci. 2007, 32, 595-610. [CrossRef]

8. Horwitz, J. Alpha-crystallin can function as a molecular chaperone. Proc. Natl. Acad. Sci. USA 1992, 89, 10449-10453. [CrossRef]

9. Basha, E.; O'Neill, H.; Vierling, E. Small heat shock proteins and $\alpha$-crystallins: Dynamic proteins with flexible functions. Trends Biochem. Sci. 2012, 37, 106-117. [CrossRef]

10. De Jong, W.W.; Caspers, G.-J.; Leunissen, J.A. Genealogy of the $\alpha$-crystallin—small heat-shock protein superfamily. Int. J. Biol. Macromol. 1998, 22, 151-162. [CrossRef]

11. Franck, E.; Madsen, O.; Van Rheede, T.; Ricard, G.; Huynen, M.A.; De Jong, W.W. Evolutionary Diversity of Vertebrate Small Heat Shock Proteins. J. Mol. Evol. 2004, 59, 792-805. [CrossRef] [PubMed]

12. Kappé, G.; Franck, E.; Verschuure, P.; Boelens, W.C.; Leunissen, J.A.M.; De Jong, W.W. The human genome encodes $10 \alpha$-crystallinrelated small heat shock proteins: HspB1-10. Cell Stress Chaperon 2003, 8, 53-61. [CrossRef]

13. Li, Z.; Li, X.; Yu, Q.-Y.; Xiang, Z.-H.; Kishino, H.; Zhang, Z. The small heat shock protein (sHSP) genes in the silkworm, Bombyx mori, and comparative analysis with other insect sHSP genes. BMC Evol. Biol. 2009, 9, 215. [CrossRef] [PubMed]

14. Hayes, D.B.; Napoli, V.; Mazurkie, A.; Stafford, W.F.; Graceffa, P. Phosphorylation Dependence of Hsp27 Multimeric Size and Molecular Chaperone Function. J. Biol. Chem. 2009, 284, 18801-18807. [CrossRef]

15. Arrigo, A.P. Small stress proteins: Chaperones that act as regulators of intracellular redox state and programmed cell death. Biol. Chem. 1998, 379, 19-26.

16. Tsvetkova, N.M.; Horváth, I.; Török, Z.; Wolkers, W.F.; Balogi, Z.; Shigapova, N.; Crowe, L.M.; Tablin, F.; Vierling, E.; Crowe, J.H.; et al. Small heat-shock proteins regulate membrane lipid polymorphism. Proc. Natl. Acad. Sci. USA 2002, 99, 13504-13509. [CrossRef]

17. Haslbeck, M. sHsps and their role in the chaperone network. Cell. Mol. Life Sci. 2002, 59, 1649-1657. [CrossRef]

18. Garrido, C.; Paul, C.; Seigneuric, R.; Kampinga, H.H. The small heat shock proteins family: The long forgotten chaperones. Int. J. Biochem. Cell Biol. 2012, 44, 1588-1592. [CrossRef]

19. Sun, Y.; Macrae, T.H. Small heat shock proteins: Molecular structure and chaperone function. Cell. Mol. Life Sci. 2005, 62, 2460-2476. [CrossRef] 
20. Murshid, A.; Gong, J.; Stevenson, M.A.; Calderwood, S.K. Heat shock proteins and cancer vaccines: Developments in the past decade and chaperoning in the decade to come. Expert Rev. Vaccines 2011, 10, 1553-1568. [CrossRef]

21. Macrae, T.H. Gene expression, metabolic regulation and stress tolerance during diapause. Cell. Mol. Life Sci. 2010, 67, 2405-2424. [CrossRef] [PubMed]

22. Hahn, D.A.; Denlinger, D.L. Energetics of Insect Diapause. Annu. Rev. Entomol. 2011, 56, 103-121. [CrossRef] [PubMed]

23. Hayward, S.A.L.; Pavlides, S.; Tammariello, S.; Rinehart, J.; Denlinger, D. Temporal expression patterns of diapause-associated genes in flesh fly pupae from the onset of diapause through post-diapause quiescence. J. Insect Physiol. 2005, 51, 631-640. [CrossRef] [PubMed]

24. Rinehart, J.P.; Li, A.; Yocum, G.D.; Robich, R.M.; Hayward, S.A.L.; Denlinger, D.L. Up-regulation of heat shock proteins is essential for cold survival during insect diapause. Proc. Natl. Acad. Sci. USA 2007, 104, 11130-11137. [CrossRef]

25. Si, F.L.; He, Z.B.; Chen, B. Cloning and expression profiling of heat shock protein DaHSP23 gene in the winter and summer diapause pupae of the onion maggot, Delia antiqua (Diptera: Anthomyiidae). Acta Entomol. Sin. 2016, 59, 402-410.

26. Fremdt, H.; Amendt, J.; Zehner, R. Diapause-specific gene expression in Calliphora vicina (Diptera: Calliphoridae)—A useful diagnostic tool for forensic entomology. Int. J. Leg. Med. 2013, 128, 1001-1011. [CrossRef]

27. Gkouvitsas, T.; Kontogiannatos, D.; Kourti, A. Differential expression of two small Hsps during diapause in the corn stalk borer Sesamia nonagrioides (Lef.). J. Insect Physiol. 2008, 54, 1503-1510. [CrossRef]

28. Lu, Y.-X.; Xu, W.-H. Proteomic and Phosphoproteomic Analysis at Diapause Initiation in the Cotton Bollworm, Helicoverpa armigera. J. Proteome Res. 2010, 9, 5053-5064. [CrossRef]

29. Zhang, B.; Zheng, J.; Peng, Y.; Liu, X.A.; Hoffmann, A.; Ma, C.-S. Stress Responses of Small Heat Shock Protein Genes in Lepidoptera Point to Limited Conservation of Function across Phylogeny. PLoS ONE 2015, 10, e0132700. [CrossRef]

30. Tachibana, S.-I.; Numata, H.; Goto, S.G. Gene expression of heat-shock proteins (Hsp23, Hsp70 and Hsp90) during and after larval diapause in the blow fly Lucilia sericata. J. Insect Physiol. 2005, 51, 641-647. [CrossRef]

31. Goto, S.G.; Kimura, M.T. Heat-shock-responsive genes are not involved in the adult diapause of Drosophila triauraria. Gene 2004, 326, 117-122. [CrossRef] [PubMed]

32. Saravanakumar, R.; Ponnuvel, K.M.; Qadri, S.M.H. Expression of metabolic enzyme genes and heat-shock protein genes during embryonic development in diapause and non-diapause egg of multivoltine silkworm Bombyx mori. Biologia 2008, 63, 737-744. [CrossRef]

33. Mestril, R.; Schiller, P.; Amin, J.; Klapper, H.; Ananthan, J.; Voellmy, R. Heat shock and ecdysterone activation of the Drosophila melanogaster hsp23 gene; a sequence element implied in developmental regulation. EMBO J. 1986, 5, 1667-1673. [CrossRef] [PubMed]

34. Amin, J.; Mestril, R.; Voellmy, R. Genes for Drosophila small heat proteins are regulated differently by ecdysone. Mol. Cell. Biol. 1991, 11, 5937-5944. [PubMed]

35. Kokolakis, G.; Tatari, M.; Zacharopoulou, A.; Mintzas, A.C. Thehsp27gene of the Mediterranean fruit fly, Ceratitis capitata: Structural characterization, regulation and developmental expression. Insect Mol. Biol. 2008, 17, 699-710. [CrossRef]

36. Liu, Z.; Yao, P.; Guo, X.; Xu, B. Two small heat shock protein genes in Apis cerana cerana: Characterization, regulation, and developmental expression. Gene 2014, 545, 205-214. [CrossRef]

37. Gaafar, N.; Volkmar, C. Evaluation of wheat ear insects in large scale field in central Germany. Agric. Sci. 2010, 1, 68-75. [CrossRef]

38. Miao, J.; Wu, Y.-Q.; Gong, Z.-J.; He, Y.-Z.; Duan, Y.; Jiang, Y.-L. Long-Distance Wind-Borne Dispersal of Sitodiplosis mosellana Géhin (Diptera: Cecidomyiidae) in Northern China. J. Insect Behav. 2012, 26, 120-129. [CrossRef]

39. Shrestha, G.; Reddy, G.V.P. Field efficacy of insect pathogen, botanical, and jasmonic acid for the management of wheat midge Sitodiplosis mosellana and the impact on adult parasitoid Macroglenes penetrans populations in spring wheat. Insect Sci. 2019, 26, 523-535. [CrossRef]

40. Wang, Y.; Long, Z.R.; Feng, A.R.; Cheng, W.N. Effects of initial population number, wheat varieties and precipitation on infestation of Sitodiplosis mosellana (Diptera: Cecidomyiidae). Acta Agric. Boreali Occident. Sin. 2015, 24, 165-171.

41. Cheng, W.; Long, Z.; Zhang, Y.; Liang, T.; Zhu-Salzman, K. Effects of temperature, soil moisture and photoperiod on diapause termination and post-diapause development of the wheat blossom midge, Sitodiplosis mosellana (Géhin) (Diptera: Cecidomyiidae). J. Insect Physiol. 2017, 103, 78-85. [CrossRef] [PubMed]

42. Cheng, W.; Li, D.; Wang, Y.; Liu, Y.; Zhu-Salzman, K. Cloning of heat shock protein genes (hsp70, hsc70 and hsp90) and their expression in response to larval diapause and thermal stress in the wheat blossom midge, Sitodiplosis mosellana. J. Insect Physiol. 2016, 95, 66-77. [CrossRef] [PubMed]

43. Tamura, K.; Stecher, G.; Peterson, D.; Filipski, A.; Kumar, S. MEGA6: Molecular Evolutionary Genetics Analysis Version 6.0. Mol. Biol. Evol. 2013, 30, 2725-2729. [CrossRef] [PubMed]

44. Doane, J.; Olfert, O. Seasonal development of wheat midge, Sitodiplosis mosellana (Géhin) (Diptera: Cecidomyiidae), in Saskatchewan, Canada. Crop. Prot. 2008, 27, 951-958. [CrossRef]

45. Cheng, W.N.; Li, J.J.; Li, Y.P.; Li, X.L.; Wu, J.X.; Wang, H.L. Quantitative analysis of ecdysteroid in adults and the pre-diapause, diapause and post-diapause larvae of wheat blossom midge, Sitodiplosis Mosellana Gehin. Acta Phytophy. Sin. 2009, 36, $163-167$.

46. Livak, K.J.; Schmittgen, T.D. Analysis of relative gene expression data using real-time quantitative PCR and the $2^{-\Delta \Delta C T}$ method. Methods 2001, 25, 402-408. [CrossRef] 
47. Zhang, T.-T.; Mei, X.-D.; Feng, J.-N.; Berg, B.G.; Zhang, Y.; Guo, Y.-Y. Characterization of three pheromone-binding proteins (PBPs) of Helicoverpa armigera (Hübner) and their binding properties. J. Insect Physiol. 2012, 58, 941-948. [CrossRef]

48. Pérez-Morales, D.; Ostoa-Saloma, P.; Espinoza, B. Trypanosoma cruzi SHSP16: Characterization of an $\alpha$-crystallin small heat shock protein. Exp. Parasitol. 2009, 123, 182-189. [CrossRef]

49. Jacobsen, J.V.; Shaw, D.C. Heat-Stable Proteins and Abscisic Acid Action in Barley Aleurone Cells. Plant Physiol. 1989, 91, 1520-1526. [CrossRef]

50. Fu, X.; Li, W.; Mao, Q.; Chang, Z. Disulfide bonds convert small heat shock protein Hsp16.3 from a chaperone to a non-chaperone: Implications for the evolution of cysteine in molecular chaperones. Biochem. Biophys. Res. Commun. 2003, 308, 627-635. [CrossRef]

51. Zhao, J.J.; Li, X.J.; Liu, Z.Z.; Cheng, W.N.; Zhu, K.Y. Cloning of heat shock protein gene SmHsp40 and its expression during diapause and under extreme temperatures stress in Sitodiplosis mosellana (Diptera: Cecidomyiidae). Acta Entomol. Sin. 2018, 61, 1253-1263.

52. Bagneris, C.; Bateman, O.A.; Naylor, C.E.; Cronin, N.; Boelens, W.C.; Keep, N.H.; Slingsby, C. Crystal Structures of $\alpha$-Crystallin Domain Dimers of $\alpha$ B-Crystallin and Hsp20. J. Mol. Biol. 2009, 392, 1242-1252. [CrossRef]

53. De Jong, W.W.A.; Leunissen, J.E.; Voorter, C. Evolution of the alpha-crystallin/small heat-shock protein family. Mol. Biol. Evol. 1993, 10, 103-126. [CrossRef] [PubMed]

54. Denlinger, D.L. Regulation of diapause. Annu. Rev. Entomol. 2002, 47, 93-122. [CrossRef]

55. Cheng, W.; Li, X.; Zhao, J.; Zhu-Salzman, K. Cloning and characterization of Methoprene-tolerant (Met) and Krüppel homolog 1 (Kr-h1) genes in the wheat blossom midge, Sitodiplosis mosellana. Insect Sci. 2020, 27, 292-303. [CrossRef]

56. Barnes, H.F. Studies of fluctuations in insect populations. VIII. The wheat blossom midge on broadbalk, 1932-1940, with a discussion of the results obtained 1927-1940. J. Anim. Ecol. 1941, 10, 94-120.

57. Yuan, F. The Wheat Blossom Midges Sitodiplosis Mosellana (Gehin) and Contarinia Tritici (Kirby): Their Plague Principle and Control; Science Press: Beijing, China, 2004. 